\title{
A Comparative Returns Performance Review of Islamic Equity Funds with Socially Responsible Equity Funds and the Broader Market Indices
}

\section{Syed Kalim Hyder Bukhari* and Mohammed Azam**}

\begin{abstract}
Islamic mutual funds and socially responsible mutual funds are two similar asset classes that incorporate negative screens in their portfolio selection process to filter out stocks that fail to meet certain ethical, social, environmental, and/or religious standards. This study uses a single-factor capital asset pricing model and an adjusted sample consisting of 224 Islamic funds and 573 socially responsible funds to examine their excess risk-adjusted returns, market volatility, and systematic risk. It also gauges the market-timing abilities of the fund managers concerned in relation to both Islamic/socially responsible and conventional market indices. While there are some differences in the risk factors of Islamic funds and socially responsible funds, both are associated with lower risks and have the same market-timing ability.
\end{abstract}

Keywords: Islamic mutual funds, capital asset pricing model, returns, systematic risk, market volatility.

\section{JEL classification: G19.}

\section{Introduction}

Since its inception a few decades ago, the Islamic finance industry has become one of the biggest success stories of modern financial diversification: it is on the brink of achieving global asset holdings in excess of US\$ 2 trillion (Ernst \& Young, 2012). Islamic investments, a key component of this industry, have experienced stellar growth in recent years following the decree issued by a leading global authority of Islamic law - the Islamic Fiqh Academy - permitting Muslims to participate in stock markets through carefully screened stocks and equities.

The number of Islamic equity funds (IEFs) worldwide has increased from merely nine in 1994 to more than 600 today. The unique

\footnotetext{
* University of Leicester, Leicester, UK.

** University of Sheffield, Sheffield, UK.
} 
characteristics of Islamic investments make them a specific type of socially responsible investment (SRI) - another market that has also witnessed tremendous growth in the last 20 years. The popularity of SRIs is attributed to increasing interest in faith-based investing as well as the growing body of business ethics literature that emphasizes good business practices and corporate social responsibility over the single-minded pursuit of profit and maximizing shareholder value.

However, in order to sustain reasonably attractive growth rates in the long term, the Islamic investments industry needs to broaden its client base by appealing to investors outside its core demographic, which consists overwhelmingly of Muslim investors. This can be achieved if Islamic investments are shown to be an adequate substitute for conventional SRIs by earning returns that are higher, or at least comparable, in order to attract non-Muslim socially responsible investors. Despite the immense size and growth of the industry, the research on Islamic finance remains extremely limited, even more so with regard to IEFs. Our findings, therefore, could prove to be a valuable contribution to the sparse literature on the subject.

The limited literature provides space for further insight into the topic. We take into account more funds and a longer time period improving coverage of the cross-sectional and time series dimensions. Further, the period of our analysis, 2009-2013, is important as far as the financial performance of SRIs and IEFs is concerned. The Islamic finance industry grew, on average, by 17 percent between 2009 and 2013; the total investment in SRIs almost doubled from below US 3 trillion in 2009 by the end of 2013. Additionally, we apply Pesaran and Smith's (1995) mean group estimation technique to the heterogeneous panel dataset of funds.

The aim of this paper is to evaluate the comparative performance of Islamic equity mutual funds and socially responsible mutual funds with their respective benchmarks. Both asset classes are also measured against the standard regional market indices to assess their attractiveness based on pure economic returns. This provides insight into how the competitiveness of IEFs and SRIs has kept pace with their rapid growth rates.

The analysis is conducted using two variations of the single-factor capital asset pricing model (CAPM) by estimating standard models of weekly returns data on IEFs and SRIs over the period January 2000 to August 2013. The first equation is Jensen's (1968) variant of the CAPM, which measures risk-adjusted performance; the second equation is 
Treynor and Mazuy's (1966) variant of the CAPM, which also measures market timing ability.

Our results broadly concur with the findings of some of the existing literature on the performance of IEFs: on average, they tend to exhibit negative alphas and betas of less than 1, and their funds managers fare poorly in outguessing the market for both Islamic and conventional benchmarks. SRI funds, however, have very similar characteristics, thereby strengthening the case for IEFs as a viable alternative to conventional SRI funds for ethical or socially conscious non-Muslim investors.

SRIs and IEFs are broadly similar in terms of their risk-return characteristics, which could make the latter more attractive to ethical or socially conscious non-Muslim investors. This proposition is even more valid in markets such as the Gulf Cooperation Council (GCC) region and Middle East and North Africa (MENA), where there is a noticeable lack or complete absence of conventional SRI instruments. Our results support this argument and indicate that SRIs and IEFs may be potential substitutes.

\section{Literature Review}

Islamic funds are characterized by their compliance with the Shari'ah or Islamic law, which defines a financial model based on shared risk and return with certain restrictions, such as the prohibition of riba (interest or usury), maysir (excessive speculation or gambling), gharar (preventable contractual ambiguity or uncertainty), and investments in industries deemed unethical or forbidden by Islamic law. In addition, all monetary and business transactions are subject to a number of secondary conditions, including (but not limited to) principle guidelines such as:

- Money is only a medium of exchange, not an asset, and hence cannot earn a return on itself.

- Risk cannot be sold or transferred, but can be shared.

- Debt cannot be sold, only exchanged at par value.

- Assets must be owned before they can be sold.

- All financial flows must be real economic transactions linked to an underlying asset.

Many renowned global financial services firms - such as Dow Jones, the FTSE, Standard \& Poor's, Thomson Reuters, MSCI and Russell now provide hundreds of Islamic indices categorized by region, industry, 
investment objective, and market capitalization. The constituents of any Islamic index, however, must satisfy the following main screening criteria:

- The company's debt-market capitalization ratio or total-debt-to-totalassets ratio must not exceed 33 percent.

- Accounts receivables and liquid assets in the form of marketable securities and bank accounts should not comprise more than 45 percent of a company's total assets, while cash and any equivalent holdings that generate interest income should not be greater than 33 percent of the company's total assets.

- Income from interest or any otherwise prohibited economic activity must be less than 15 percent of total revenue and be donated to charity.

Although the filters applied by the Shari'ah supervisory boards of various index providers are largely homogeneous, the complexity of Islamic law and jurisprudential disagreements between its main schools of thought mean that the exact values of the stated financial ratios can differ. As a result, there is a noticeable lack of consensus and standardization in this regard, which may be cause for concern about the growth prospects of inter-regional Islamic investment.

In contrast, SRIs are not subject to any predetermined financial parameters in their screening process. Their filters also incorporate criteria such as compliance with environmental regulations, corporate transparency, and companies' or countries' human rights records - factors that are not taken into account when filtering stocks for Islamic prohibitions. Another important distinction is that SRIs' ethical committees are generally advisory bodies while the opinions of Shari'ah supervisory boards are binding and essential.

Hayat and Kräussl (2011) posit that IEFs "may as well be an interesting investment for non-Muslims, especially for those who see IEFs as a type of SRI." The literature appears to support this assertion: for example, Renneboog, Ter Horst, and Zhang (2008) classify Islamic (and other religious) funds as a form of socially responsible investing. Pornography, tobacco, arms manufacturing, alcoholic beverages, and gambling are generally excluded by both.

The difference between Islamic funds and other SRIs lies in the types of businesses they avoid: Islamic funds avoid investments in interestbased financial institutions - such as banks, mortgage and insurance firms, and hedge funds - and pork producers, which usually pass SRI filters 
(Renneboog et al., 2008). However, Forte and Miglietta (2011) argue that IEFs should be excluded from any filters, including SRI filters. They are reluctant to classify IEFs as socially responsible funds because the latter normally have the primary objective of profitable investing with social responsibility screens added potentially due to the fund manager's moral beliefs or to minimize legal and environmental issues. IEFs, on the other hand, apply primarily a religious screen with the profit motive being secondary. Further, their compliance with Shari'ah principles suggests that IEFs may include some investments that would be excluded under most SRI principles. For instance, IEFs are more likely to invest in countries such as Syria, Iran, and Saudi Arabia, which the conditions of most SRI funds would exclude (Forte \& Miglietta, 2011).

Commenting on the expected performance of socially responsible funds, Geczy, Stambaugh, and Levin (2005) suggest that, "investors who allocate their wealth to socially responsible mutual funds pay a price." This is likely because applying socially responsible principles creates additional overheads for the fund manager in two ways: First, fund managers face limitations in the universe of possible investments for the fund. Second, fund managers need to spend time and resources evaluating the social principles of potential investments, which may have no direct correlation with their economic attractiveness.

To some extent, Derwall, Guenster, Bauer, and Koedijk (2005) contradict these results: they measure social responsibility by ecological efficiency and find that portfolios comprising the equity securities of the most socially responsible companies tend to have higher average returns than their lower ranked counterparts. Although this precludes the influence of an active fund manager in determining portfolio returns, the study suggests there may be an ambiguous relationship between portfolio returns and imposing socially responsible principles on investment.

With respect to whether the Islamic funds screening process has a noticeable negative impact on returns and efficiency when compared to conventional funds and investments, the literature remains inconclusive. While Geczy et al. (2005) point to many standard stocks delivering significantly positive abnormal returns, empirical studies such as Abdelsalam, Fethi, Matallín, and Tortosa-Ausina (2014) compare restricted Islamic portfolios with their unrestricted counterparts and find no significant performance differences between the two. They hypothesize that the limited investment asset universe may be offset by the financial ratios criteria imposed by Islamic screens that exclude companies in debt 
and excessive leverage - often indicators of poor performance. For example, Enron and WorldCom were excluded from the constituent lists of Islamic benchmarks shortly before they went bankrupt.

While the literature on SRIs has grown in parallel with the industry itself, academic research on Islamic investments has not kept pace with the expansion and proliferation of IEFs worldwide. Studies on IEF performance are scarce. The two most comprehensive and commonly cited works on the subject, Hayat and Kräussl (2011) and Hoepner, Rammal, and Rezec (2011), are both fairly recent. Prior research is fairly limited in terms of scale, sample size, and time periods, and focuses mostly on Malaysia, which remains the hub of Islamic finance despite the Arab states of the GCC (Saudi Arabia, Qatar, Kuwait, and the United Arab Emirates) collectively accounting for a larger proportion of Shari'ah-compliant assets worldwide.

Hayat and Kräussl (2011) use a survivorship bias-adjusted sample of 145 IEFs categorized into five regions: global, Malaysia, Asia-Pacific, Europe and the Middle East, and North America. The analysis applies Jensen's (1968) model and Treynor and Mazuy's (1966) CAPM regressions to weekly pricing data for the period 2000-09, using Islamic as well as conventional benchmarks as market proxies. The results indicate that IEFs have, on average, negative alphas (risk-adjusted returns) and betas (systematic risk) of less than 1. Islamic fund managers are found to be poor market timers and the lack of any significant downside risk rules it out as a potential explanation for the underperformance of IEFs.

While Hoepner et al. (2011) also employ a CAPM regression analysis - albeit a variant in the form of a multi-factor Carhart model - to a larger sample of the monthly returns of 265 IEFs over a very similar time period, they fail to conclude that IEFs outperform or underperform relative to equity markets in general. Rather, they find that IEFs from the six largest Islamic financial centers in their study (the GCC countries and Malaysia) are "competitive or even outperform international equity market benchmarks." This implies that IEF performance has a visible home bias and tends to benefit from close proximity to its main markets. The authors also observe that IEFs clearly prefer small-caps and growth stocks - a finding with which Hayat and Kräussl (2011) concur.

The discrepancies between these two sets of results are most likely caused by two factors: 
- Sample size and characteristics. Although the GCC/MENA region is the largest regional shareholder of total Islamic assets worldwide, it is severely underrepresented by Hayat and Kräussl (2011). Only three out of a total of 145 funds are from the Middle East, comprising a mere 2 percent of their sample. In contrast, Hoepner et al. (2011) use a sample of 265 funds, which is both larger and proportionally diverse. The particulars and sources of data are also markedly different. Hayat and Kräussl use weekly pricing data from Bloomberg, adjusted for dividends and capital gains, while Hoepner et al. obtain their data from Eurekahedge's database, which consists of unadjusted monthly returns.

- Model specification. The multi-factor conditional Carhart CAPM model selected by Hoepner et al. (2011) introduces additional factors for size and the value of the book-to-market ratio, for which the single-factor models used by Hayat and Kräussl (2011) do not account. Although both studies convert the pricing data into US dollars, Hayat and Kräussl use a single risk-free rate while Hoepner et al. choose different interest rates for different regions in their specification.

Abdelsalam et al. (2014) employ partial frontier and quantile regression methods instead of the CAPM as the main component of their analytical framework. Since their main aim is to assess the performance and efficiency of Islamic and SRI mutual funds relative to each other, they have very little to say about fund performance relative to established benchmarks and the market timing ability of fund managers. Nevertheless, Abdelsalam et al. conclude that, despite differences in the portfolio management and screening criteria of IEFs and SRI funds, variations in performance are found only for "some of the quantiles of the conditional distribution of mutual fund performance."

Based on the differences in opinion of the various studies reviewed above, we propose to empirically evaluate differences in the risk and return characteristics of both SRIs and IEFs. This supports the assertion made by Forte and Miglietta (2011) that the two investment classes are fundamentally different, unlike Renneboog et al. (2008), who classify IEFs together with SRIs.

Fund managers carry out two types of activities: security selection and market timing (Kon, 1983). Professional fund managers are assumed to have significant positive skills in either activity to justify the payment of fees. If, for example, they cannot deliver significant outperformance and if any performance in the fund is purely due to changes in the market, fund managers may not be able to justify charging a fee because investors could, 
theoretically, obtain the same performance by investing in a diversified portfolio on their own. The available empirical evidence, however, suggests that market timing ability varies between fund managers. Cuthbertson, Nitzsche, and O'Sullivan (2010) use a nonparametric model introduced by Jiang (2003) to examine the market timing ability of mutual fund managers in the UK. The authors find that, on average, fund managers tend to mistime the market, leading to negative returns.

Abdullah, Hassan, and Mohamad (2007) use a similar method to ours (the Treynor-Mazuy model) to estimate the ability of Malaysian fund managers in the government, nongovernment, conventional, and Islamic sectors to market-time. The authors find that all four categories of fund managers showed negative market timing ability over all periods before, during, and after a financial crisis (the Asian crisis of 1997). Hayat and Kräussl (2011) similarly find that IEF managers have poor market timing ability when measured against both conventional and Islamic benchmarks and using both the Treynor-Mazuy and nonparametric models.

There are several reasons for this apparent contradiction with respect to the theory. Cuthbertson et al. (2010) argue that it may be due to the impact of cash flow on fund behavior: when markets are rising, funds tend to experience investor cash inflows, which leads to a higher cash position vis-à-vis their holdings in risky securities and to lower market exposure and returns. The reverse is true when markets are falling. Further, fund managers may posit a relationship between the general price level of the market and market volatility where, even if they believe that the market as a whole is expected to rise further, they do not increase the portfolio's market exposure due to concerns about increased volatility. On the basis of this argument, we seek to explore the market timing ability of fund managers for both IEFs and SRIs.

\section{Theoretical Framework}

The classic model measuring fund performance is Jensen's (1968) alpha model, ${ }^{1}$ which is based on the CAPM and is denoted as follows:

$$
R_{p t}-R_{f t}=\alpha_{p}+\beta_{p}\left(R_{m t}-R_{f t}\right)+\varepsilon_{p t}
$$

where $\mathrm{R}_{\mathrm{pt}}$ is the return on portfolio (or fund) $p$ at time $t, \mathrm{R}_{\mathrm{ft}}$ is the return of some risk-free asset at time $t,{ }^{2}$ the USD ten-year swap rate, $\mathrm{R}_{\mathrm{mt}}$, is the

\footnotetext{
${ }^{1}$ See Patro (2001) for an application of Jensen's alpha to mutual funds.

${ }^{2}$ This study uses the same risk-free asset as Hayat and Kräussl (2011).
} 
return of the market portfolio at time $t$, and $\varepsilon_{p t}$ is the error term. $\alpha_{\mathrm{p}}$ is Jensen's (1968) alpha normally interpreted as the excess performance of a fund relative to that of the market portfolio and $\beta_{p}$ is the beta factor or the portfolio's sensitivity to changes in the underlying market portfolio.

A risk-free rate of return inherently contravenes one of the fundamental principles of Islamic finance, but the possibility of such a benchmark ever being Shari'ah-compliant does exist. In principle, the lack of suitable alternatives and the wide use of risk-free rates in Islamic equities using the CAPM employs some kind of standard risk-free rate, be it the T-bill rate or the USD ten-year swap rate. There is a certain paradigm here to which we have adhered for the sake of academic consistency.

Since only one factor is used as a benchmark (the market proxy), the model above is a single-factor model. A significant problem associated with single-factor models is the comparatively poor $\mathrm{R}^{2}$ of the regression. As a result, multi-factor models are proposed as a way to improve the proportion of the variance explainable by the regression equation. Fama and French (1993) provide an influential three-factor model, which includes an additional factor for size (small vs. big companies or SMB) and one for the ratio of the book-to-market value ("value" vs. "growth" stocks or HML):

$R_{p t}-R_{f t}=\alpha_{p}+\beta_{p m}\left(R_{m t}-R_{f t}\right)+\beta_{p S M B} S M B_{t}+\beta_{p H M L} H M L_{t}+\varepsilon_{p t}$

Treynor and Mazuy (1966) introduce another important addition to the standard CAPM - a factor testing whether the fund can employ marketing timing procedures to improve its returns. Applying their variant to equation (1) yields:

$R_{p t}-R_{f t}=\alpha_{p}+\beta_{p}\left(R_{m t}-R_{f t}\right)+\gamma_{p}\left(R_{m t}-R_{f t}\right)^{2}+\varepsilon_{p t}$

where $\gamma_{p}$ is a factor determined by the regression, representing the market timing ability of the manager of portfolio $p$.

\section{Data and Sample Description}

The data for this study was collected from a Bloomberg terminal, consistent with the methodology used by Hayat and Kräussl (2011). The data provided by Bloomberg includes distributions and is adjusted for cash and capital changes such as dividends, redemptions, and liquidation. All the data reflects five-day percentage price changes (converted into US dollars): 


$$
\left[\frac{\text { Last trade }- \text { closing price five days ago }}{\text { Closing price five days ago }}\right] * 100
$$

The frequency of the pricing data has been adjusted from daily to weekly because this allows us to avoid the excessive volatility of daily price changes. Moreover, it prevents any loss of information resulting from the far lower number of observations in a monthly time series. We expand on Hayat and Kräussl's (2011) timeframe by investigating the entire period from 3 January 2000 to 31 August 2013. This yields a maximum of 713 weekly returns figures obtained for each fund.

Next, we attempt to address the problem of finding appropriate benchmarks. The data shows that some of these funds have a regional or global focus; therefore, a fund may be domiciled in one country (Saudi Arabia) but invest regionally (the Middle East) or globally. A potential way of dealing with international funds is to benchmark them against a suitable global equity index, but Gregory and Whittaker (2007) argue that many SRI funds show evidence of home bias and variation in the degree of bias between funds. Thus, they recommend benchmarking against the MSCI World index and including some home factors to account for home bias. This increases the number of factors in the required regression by two. Adjusting equations (1) and (3) for Jensen's alpha and the Treynor-Mazuy variant respectively, we have:

$$
\begin{aligned}
& R_{p t}-R_{f t}=\alpha_{p}+\beta_{w p}\left(R_{w t}-R_{f t}\right)+\beta_{w d}\left(R_{w t}-R_{m t}\right)+\varepsilon_{p t} \\
& R_{p t}-R_{f t}=\alpha_{p}+\beta_{w p}\left(R_{w t}-R_{f t}\right)+\gamma_{w p}\left(R_{w t}-R_{f t}\right)^{2}+\beta_{w p}\left(R_{w t}-\right. \\
& \left.R_{m t}\right)+\varepsilon_{p t}
\end{aligned}
$$

where $\mathrm{R}_{\mathrm{ft}}$ and $\mathrm{R}_{\mathrm{mt}}$ are the returns on the domestic and world benchmark indices, respectively. However, the dataset does not contain enough information to ascertain the true origin of the fund - for example, a fund may be domiciled in the Cayman Islands, but its operations may be located elsewhere in the world - and therefore Gregory and Whittaker's (2007) adjustments for home bias cannot be incorporated.

Having collected data on the relevant funds from the Bloomberg database, the number of funds is filtered using a methodology simplified from that of Hayat and Kräussl (2011). Funds with data missing for more than ten consecutive weeks are removed from the sample, as are those with fewer than 30 readings over the entire 2000-13 period and those with an inception date of later than January 2012. The only adjustments made to the original data are with respect to funds that either have insufficient 
overall observations or large gaps in their data (namely ten consecutive weeks), and these are simply excluded. While Hayat and Kräussl (2011) attempt to fill in periods of missing data by taking the averages of the preceding two periods for which data is available, we have opted to leave missing data as is. This ensures that the regressions conducted are based only on the data obtained from Bloomberg.

The dataset contains an adjusted sample of 224 Islamic funds with the following geographic focus: global, GCC/MENA, Malaysia, Asia-Pacific, emerging markets, North America, and Europe. This represents an increase of 54.5 percent from Hayat and Kräussl's (2011) sample size of 145 funds. Moreover, the authors critically underrepresent funds from the GCC/MENA, one of the two most important regional markets in global Islamic finance. Finally, our sample also includes liquidated funds, thereby eliminating the possibility of our results suffering from an upward bias in returns.

Information on the sample of funds is summarized below in Table 1. Further, the dataset includes a number of SRI funds to be compared with the selected Islamic funds. In all, 573 SRI funds are selected after applying the appropriate filters to the Bloomberg data. Table 2 gives the geographic distribution of the SRI funds and the benchmarks used for comparison.

Table 1: Geographic distribution of Islamic funds and benchmarks

\begin{tabular}{|c|c|c|c|}
\hline \multicolumn{2}{|c|}{ Number of funds } & \multicolumn{2}{|c|}{ Benchmarks } \\
\hline Region & Sample & Islamic & Conventional \\
\hline Global & 73 & $\begin{array}{l}\text { Dow Jones Islamic Markets } \\
\text { Index }\end{array}$ & MSCI World Index \\
\hline GCC/MENA & 12 & $\begin{array}{l}\text { Dow Jones Islamic Markets } \\
\text { GCC Index }\end{array}$ & Tadawul All Shares Index \\
\hline Malaysia & 55 & $\begin{array}{l}\text { Kuala Lumpur Syariah } \\
\text { Index + MSCI Malaysia } \\
\text { Islamic Index** }\end{array}$ & $\begin{array}{l}\text { FTSE Bursa Malaysia KLCI } \\
\text { Index }\end{array}$ \\
\hline Asia-Pacific & 50 & $\begin{array}{l}\text { Dow Jones Islamic Markets } \\
\text { Asia Pacific Index }\end{array}$ & $\begin{array}{l}\text { Dow Jones Asian Titans } \\
\text { Index }\end{array}$ \\
\hline $\begin{array}{l}\text { Emerging } \\
\text { markets }\end{array}$ & 18 & $\begin{array}{l}\text { Dow Jones Islamic } \\
\text { Emerging Markets Index }\end{array}$ & $\begin{array}{l}\text { MSCI Emerging Markets } \\
\text { Index }\end{array}$ \\
\hline North America & 7 & Dow Jones US Islamic Index & S\&P500 Index \\
\hline Europe & 9 & $\begin{array}{l}\text { Dow Jones Islamic Markets } \\
\text { Europe Index }\end{array}$ & FTSE 100 Index \\
\hline Total & 224 & & \\
\hline
\end{tabular}

Note: ${ }^{*}$ denotes a change in benchmark because the Kuala Lumpur Syariah Index was decommissioned in 2008 and returns from the MSCI Malaysia Islamic Index substituted. 
Table 2: Geographic distribution of SRI funds and benchmarks

\begin{tabular}{lcll}
\hline \multicolumn{2}{c}{ Number of funds } & \multicolumn{2}{c}{ Benchmarks } \\
\hline Region & Sample & \multicolumn{1}{c}{ SRI } & \multicolumn{1}{c}{ Conventional } \\
\hline Global & 230 & $\begin{array}{l}\text { Dow Jones Sustainability } \\
\text { Worldwide Composite }\end{array}$ & MSCI World Index \\
Europe & 193 & $\begin{array}{l}\text { Index } \\
\text { Dow Jones Sustainability } \\
\text { Eurozone (no tobacco, } \\
\text { alcohol, arms, adult } \\
\text { entertainment industries) } \\
\text { Index } \\
\text { Dow Jones Sustainability }\end{array}$ & Fon Index \\
Asia-Pacific & 104 & $\begin{array}{l}\text { Worldwide Composite } \\
\text { Index }\end{array}$ \\
North America & 46 & $\begin{array}{l}\text { MSCI KLD 400 Social } \\
\text { Index (US) }\end{array}$ & S\&P500 Index \\
Total & 573 & & \\
\hline
\end{tabular}

\section{Methodological Framework and Analysis}

Given that we are using panel data that consists of heterogeneous groups, we apply Pesaran and Smith's (1995) mean group technique. Equations (1) and (2) are estimated separately for each group in both categories (IEFs and SRIs) and the average of the coefficients computed so that the intercepts capture individual unobserved effects. Although excess returns are in deviation form, the data is not nonstationary. Nonetheless, to ensure that all the variables are stationary, the ADF test is applied. All the variables are $\mathrm{I}(0)$.

Similar to Hayat and Kräussl (2011), we conduct a CAPM analysis but for a larger sample of funds and a longer sample period. The sample of 224 IEFs and 573 SRIs is investigated using the CAPM regression described in equation (1). Individual regressions are run for each of the funds and their alpha and beta coefficients estimated. After confirming the individual significance of the coefficients, the mean group estimators are reported. The purpose of this procedure is to consider the heterogeneity of the individual funds. Table 3 gives the regression results for the IEFs against both Islamic and conventional benchmarks, summarized by region. 
Table 3: Mean group estimators of IEF alphas and betas by region

\begin{tabular}{lllllllll}
\hline & \multicolumn{3}{c}{ Islamic benchmarks } & \multicolumn{3}{c}{ Conventional benchmarks } \\
\cline { 2 - 9 } Region & \multicolumn{1}{c}{$\boldsymbol{\alpha}$} & \multicolumn{1}{c}{$\boldsymbol{\beta}$} & $\mathbf{R}^{2}$ & Obs. & $\boldsymbol{\alpha}$ & \multicolumn{1}{c}{$\boldsymbol{\beta}$} & $\mathbf{R}^{2}$ & Obs. \\
\hline Overall & -0.0057 & $0.8105^{* *}$ & 0.5409 & 224 & -0.0068 & $0.7739^{* *}$ & 0.5358 & 224 \\
& $(0.0094)$ & $(0.2588)$ & & & $(0.0085)$ & $(0.2350)$ & & \\
Global & -0.0091 & $0.7105^{* *}$ & 0.4542 & 73 & -0.0098 & $0.6810^{* *}$ & 0.4580 & 73 \\
& $(0.0094)$ & $(0.2772)$ & & & $(0.0092)$ & $(0.2684)$ & & \\
GCC/MENA & $0.0105^{* *}$ & $1.1657^{* *}$ & 0.2651 & 12 & 0.0044 & $0.9367^{* *}$ & 0.3225 & 12 \\
& $(0.0076)$ & $(0.1974)$ & & & $(0.0064)$ & $(0.1779)$ & & \\
Malaysia & $-0.0074^{* *}$ & 0.7902 & 0.7526 & 55 & -0.0068 & $0.8079^{* *}$ & 0.7772 & 55 \\
& $(0.0046)$ & -0.0993 & & & $(0.0052)$ & $(0.1131)$ & & \\
Asia-Pacific & -0.0030 & $0.8646^{* *}$ & 0.5347 & 50 & -0.0057 & $0.7796^{* *}$ & 0.472 & 50 \\
& $(0.0103)$ & -0.3090 & & & $(0.0092)$ & $(0.2757)$ & & \\
Emerging markets & -0.0068 & $0.8537^{* *}$ & 0.3728 & 18 & -0.0066 & $0.8648^{* *}$ & 0.3826 & 18 \\
& $(0.0072)$ & $(0.2132)$ & & & $(0.0068)$ & $(0.2019)$ & & \\
North America & -0.0043 & $0.8775^{* *}$ & 0.6547 & 7 & -0.0056 & $0.8405^{* *}$ & 0.6286 & 7 \\
& $(0.0089)$ & $(0.1834)$ & & & $(0.0077)$ & $(0.1424)$ & & \\
Europe & -0.0041 & $0.8338^{* *}$ & 0.6001 & 9 & -0.0039 & $0.8369^{* *}$ & 0.5656 & 9 \\
& $(0.0078)$ & $(0.1961)$ & & & $(0.0081)$ & $(0.1989)$ & & \\
\hline
\end{tabular}

Note: Figures in brackets represent standard deviations. ${ }^{* *}$ Significant at $1 \%$ level.

Source: Authors' calculations.

The results show that the IEF betas are lower than those of their respective Islamic as well as conventional benchmarks in the case of all but one region. Furthermore, the IEFs tend to have negative alpha values, although these are statistically insignificant for most of the countries and regions tested. An exception is Malaysia where investors see an alpha of 0.74 percent when compared with the Islamic benchmark.

The GCC/MENA region, however, shows a statistically significant positive alpha of 1.05 percent and a positive beta of 1.17 when compared with the Islamic benchmark. These differences from the other regions are not as prominent when the data is compared with the conventional benchmark for GCC/MENA (the Tadawul All-Share Index). However, it still has a positive, if statistically insignificant, alpha and a beta closest to 1 out of all the regions in the category.

Overall, these results are consistent with Hayat and Kräussl (2011): IEF managers generally tend to underperform relative to conventional benchmarks, but the effect is not statistically significant. One notable divergence, however, is that our regressions generate substantially smaller negative alphas across the board for all IEF regions and, therefore, exhibit 
significantly less drag on performance compared to previous estimations. IEFs also tend to be low-beta funds compared to the conventional benchmarks - again, this is broadly similar to the findings of Hayat and Kräussl (2011). According to the equality test performed on the mean group betas of IEFs in various regions, the beta of the Islamic benchmark in the MENA countries is significantly different from that of the conventional benchmarks; the rest show no significant differences.

In contrast to Hayat and Kräussl's (2011) methodology, we have used a larger sample of SRIs than IEFs. Table 4 gives the regression results for the SRIs against both SRI and conventional benchmarks. Unlike the IEF sample, the equality test indicates that the SRI benchmarks in the global, Europe, and overall categories are significantly different from their respective conventional benchmarks.

Table 4: Mean group estimators of SRI alphas and betas by region

\begin{tabular}{lllllllll}
\hline & \multicolumn{3}{c}{ SRI benchmarks } & \multicolumn{4}{c}{ Conventional benchmarks } \\
\cline { 2 - 9 } Region & \multicolumn{1}{c}{$\boldsymbol{\alpha}$} & $\boldsymbol{\beta}$ & $\mathbf{R}^{2}$ & Obs. & $\boldsymbol{\alpha}$ & $\boldsymbol{\beta}$ & $\mathbf{R}^{2}$ & Obs. \\
\hline Overall & -0.0051 & $0.8435^{* *}$ & 0.7051 & 573 & -0.0026 & $0.9225^{* *}$ & 0.7162 & 573 \\
& $(0.0077)$ & $(0.1908)$ & & & $(0.0075)$ & $(0.1939)$ & & \\
Global & -0.0053 & $0.8550^{* *}$ & 0.7337 & 230 & -0.0035 & $0.9076^{* *}$ & 0.7311 & 230 \\
& $(0.0081)$ & $(0.1981)$ & & & $(0.0084)$ & $(0.212)$ & & \\
Europe & -0.0064 & $0.8056^{* *}$ & 0.7475 & 193 & -0.0007 & $0.9754^{* *}$ & 0.7475 & 193 \\
& $(0.0070)$ & $(0.1510)$ & & & $(0.0021)$ & $(0.1589)$ & & \\
Asia-Pacific & -0.0041 & $0.8251^{* *}$ & 0.5098 & 104 & -0.0050 & $0.8229^{* *}$ & 0.5884 & 104 \\
\multirow{2}{*}{ North America } & $-0.0083)$ & $(0.2242)$ & & & $(0.0070)$ & $(0.1855)$ & & \\
& -0.0011 & $0.9866^{* *}$ & 0.8260 & 46 & -0.0005 & $0.9997^{* *}$ & 0.8578 & 46 \\
& $(0.0053)$ & $(0.1493)$ & & & $(0.0052)$ & $(0.1426)$ & & \\
\hline
\end{tabular}

Note: Figures in brackets represent standard deviations. ${ }^{* *}$ Significant at $1 \%$ level.

Source: Authors' calculations.

The CAPM regressions on the SRI funds suggest that they behave similarly to IEFs. While some negative alpha is generated in each of the regions selected for analysis, the differences are not statistically significant. Further, in each region, the SRI funds tend to be low-beta funds when measured against their SRI and conventional benchmarks. Our analysis of SRI fund performance indicates that they have higher betas vis-à-vis their conventional benchmarks when compared with the SRI benchmarks. This implies that the SRIs selected operate more like "normal" investments than those included as SRI benchmarks. A comparison of the mean group estimators of the IEF and SRI samples yields significant differences in the global, North America, and overall categories. 
Hayat and Kräussl (2011) initially ask whether IEFs might be an interesting investment option for non-Muslims, particularly those who tend to see IEFs as a type of SRI. Although the authors do not pursue the question, based on the results obtained it would appear that:

- IEFs and SRIs are similar in that they tend to have betas of less than 1 vis-à-vis their respective as well as conventional benchmarks, which suggests that they are less risky than the market portfolio. This makes them an attractive asset class for risk-averse investors during periods of excess market volatility.

- Both IEFs and SRIs tend to underperform slightly relative to their respective benchmarks and conventional benchmarks, although this is statistically insignificant.

It is prudent to point out that the results presented thus far have not yet taken fees into account. Were we to do so, we could argue that both IEFs and SRIs are likely to be unattractive investments in general from a simple risk-return perspective: the purchaser of a basket of these funds would tend to see lower risk than the market, but incur the cost of the fees and a slight performance drag due to a small negative alpha. At the same time, such considerations are unlikely to be of much significance to the socially conscious investor. As mentioned earlier, the idea behind an SRI is to assess a value proposition based on metrics other than maximizing returns, even if doing so incurs a small opportunity cost.

As Hayat and Kräussl (2011) explain, the point of using the TreynorMazuy model to vary the regression is to test whether the same conclusions can be drawn with regard to fund performance and systematic risk under conditions of varying systematic risk. The Treynor-Mazuy model, described in equation (3), introduces a market timing ability coefficient (gamma). A statistically significant gamma value would suggest that the manager of that particular fund (or group of funds) has significant market timing ability, indicating his or her managerial skills. The Treynor-Mazuy regression is conducted with the same funds and geographic focus as for the standard CAPM regressions, and the funds are compared with the same benchmarks. Table 5 gives the regression results for the sample of IEFs.

The results indicate that IEF managers in the GCC/MENA region have negative market timing ability vis-à-vis the IEF benchmark: their poor market timing has, in turn, some detrimental effect on performance. IEF managers also show negative market timing ability when compared with conventional and Islamic benchmarks in the other regions, although this 
effect is not statistically significant. These results are consistent with those of Hayat and Kräussl (2011), and suggest that IEF managers seem able to engage in market timing ability at an individual level, but cannot outguess the Islamic equity market as a whole. 


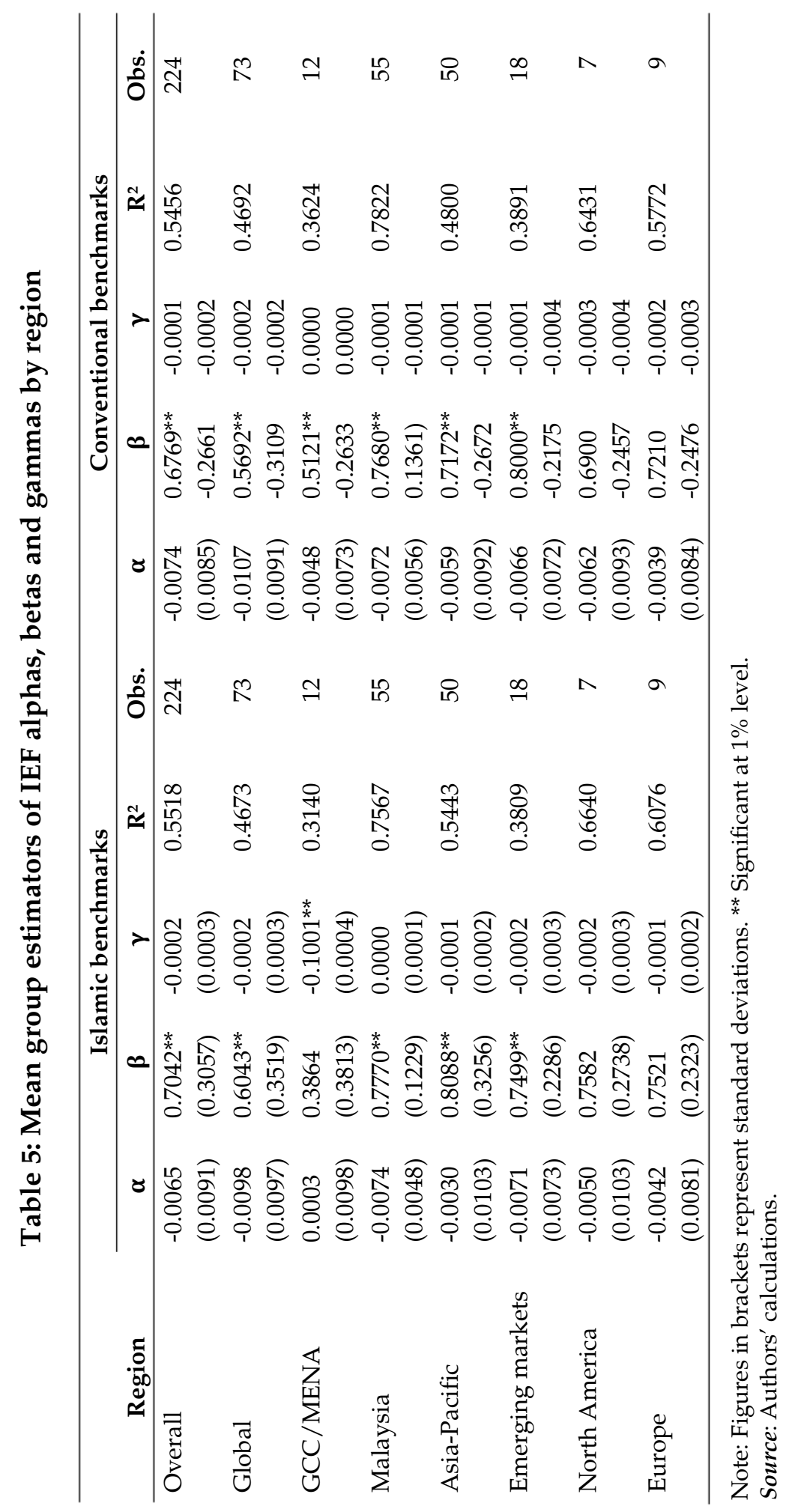


To investigate the market timing ability of individual IEF managers, we employ Hayat and Kräussl's (2011) methodology and plot a histogram of the $t$-values for the gamma of each individual fund manager in the sample of 224 IEFs (see Figure 1).

Figure 1: Histogram of t-statistics of market timing factor for all IEFs

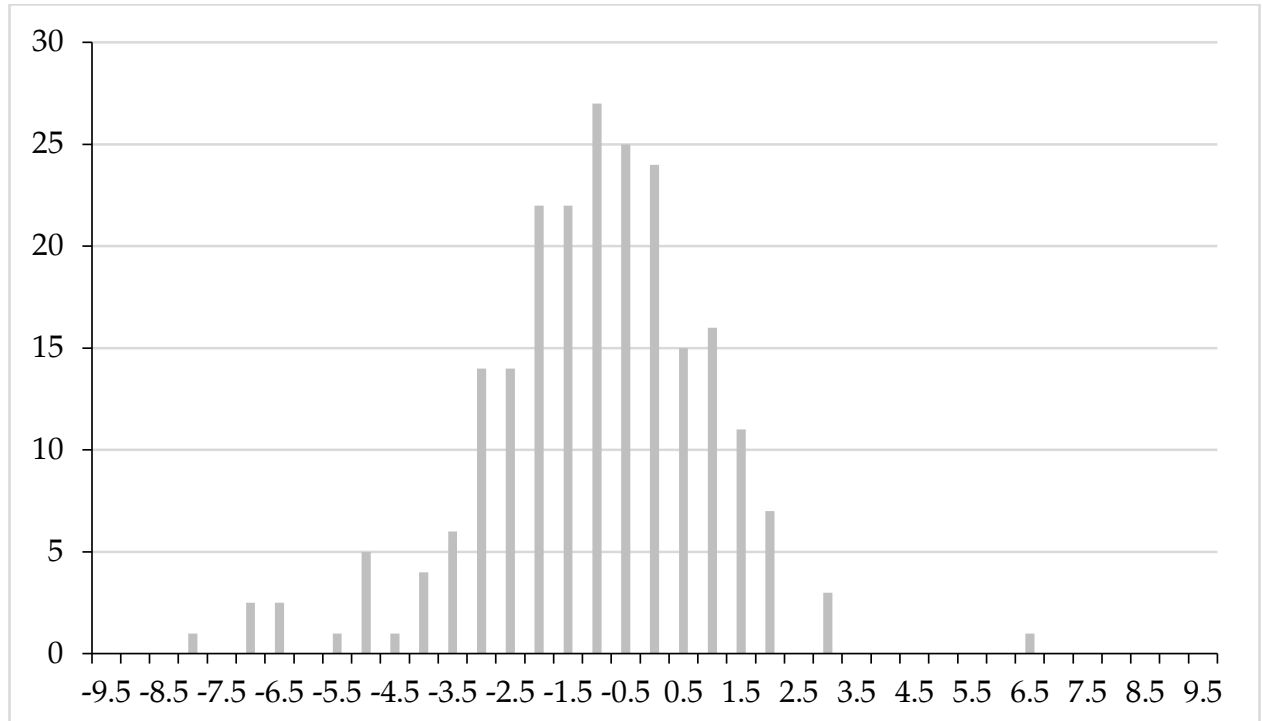

Note: $\mathrm{n}=224$.

The distribution of $\mathrm{t}$-statistics strongly suggests that fund managers do not exhibit strong market timing ability. The distribution is more negatively skewed with a comparatively large number of fund managers exhibiting negative market timing ability (only one fund achieved a tstatistic in the $+6.5-7.0$ band). These results appear to support the finding that some IEF managers do attempt to market-time, but are not particularly successful in doing so. A similar analysis is conducted for the SRI sample and is summarized in Table 6. 


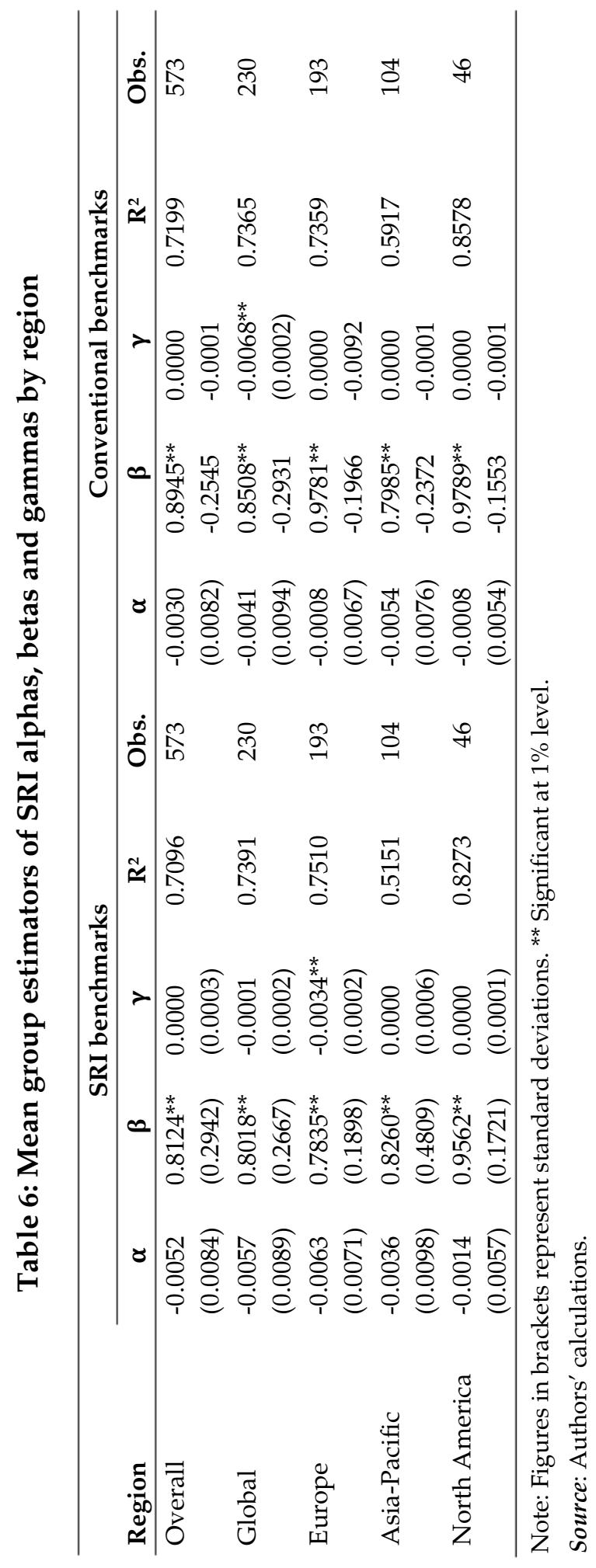


The results for the SRI funds are similar to those for the IEFs. SRI fund managers generally show poor market timing ability globally when compared with the conventional benchmark (the MSCI World index) and in Europe when compared with an SRI benchmark. Figure 2 plots a histogram of the t-statistics for the gamma values of the SRI funds in the sample.

Figure 2: Histogram of $t$-statistics of market timing factor for all SRI funds

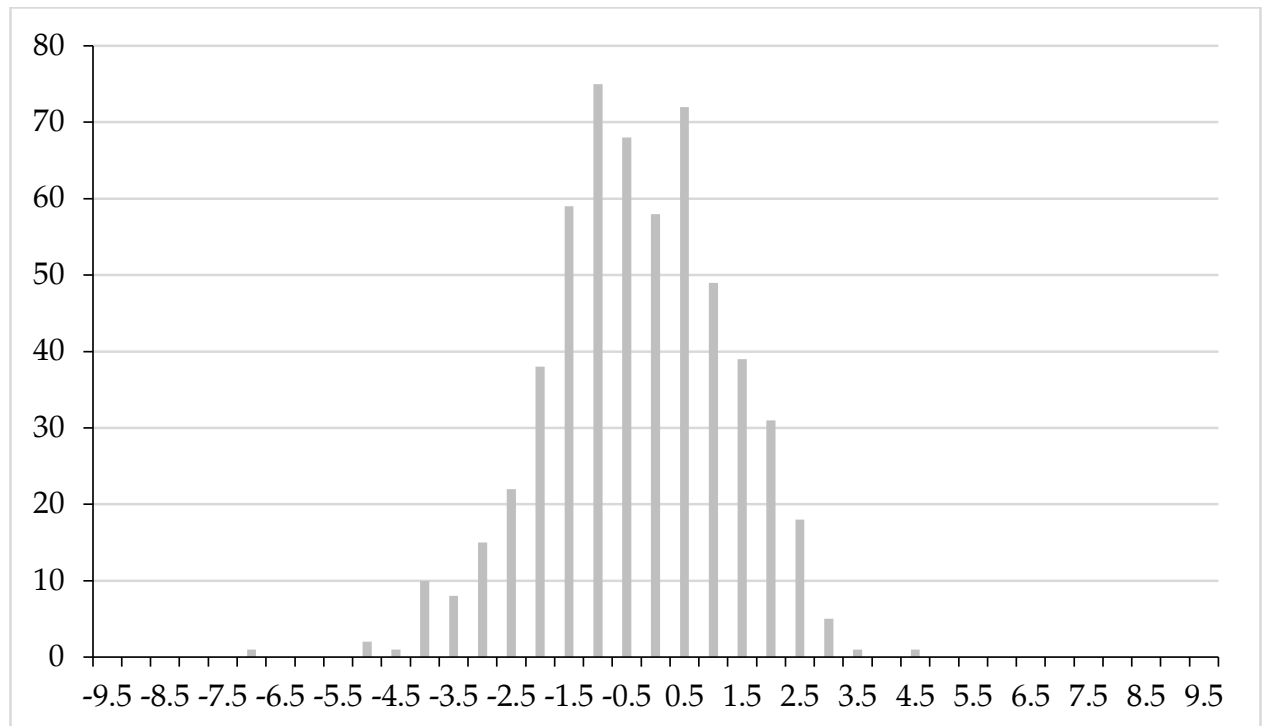

Note: $\mathrm{n}=573$.

Similar to the IEF sample, the distribution of $\mathrm{t}$-scores for the market timing ability factor is slightly negatively skewed, which suggests that SRI managers attempt to market-time, but do not have strong market timing abilities. In most cases, their attempts to do so lead to a drag on the performance of the fund.

These results reinforce our earlier suggestion with respect to IEFs that fund managers attempt to time their purchases and sales in the market, but that this activity is generally detrimental to the returns they obtain. These results are in line with the existing literature on market timing by funds in general (see Cuthbertson et al., 2010) and for both conventional and Islamic funds (see Abdullah et al., 2007; Hayat \& Kräussl, 2011). This diminishes the likelihood of negative market timing ability being detrimental specifically to IEFs. 


\section{Conclusion}

To date, this study is the largest examination of the risk and return performance characteristics of IEFs and SRI funds using the CAPM analytical framework. For instance, we have increased the number of IEFs examined simultaneously to 224 from Hayat and Kräussl's (2011) sample of 145 , and included a large sample $(n=573)$ of SRI funds for a period of 13 years. This has allowed some broad conclusions to be drawn from the universe of IEFs and SRI funds.

There are certain similarities between the risk and return performance of IEFs and SRIs: they tend to be structured such that they have low betas against their individual benchmarks and broader market benchmarks. From a simple economic perspective, neither IEFs nor SRIs appear to be attractive investments: our evidence suggests that both IEF and SRI fund managers show a statistically insignificant alpha over the entire sample period, and while fund managers have tried to time their investments in the market, they have not generally been successful. This explains their statistically insignificant negative performance over the sample period in practically all the geographical groups tested. There is little evidence in the data to suggest that the education and experience of fund managers is manifested in better market timing ability or fund performance. In aggregate, actively managed funds in general - including IEFs and SRIs - tend to underperform relative to the market before accounting for fees.

That said, the increasing prevalence of SRIs as a legitimate asset class in recent decades indicates a growing number of socially responsible investors who are driven by more than purely economic motives. Therefore, given the broadly similar risk-return characteristics of IEFs and SRIs, IEFs might well appeal to the socially conscious non-Muslim investor as a viable alternative, particularly in regional markets such as the GCC/MENA area, among others, where there is a noticeable lack or even complete absence of conventional SRI instruments. Finally, the low betas of IEFs in general with respect to both Islamic and conventional market indices make IEFs an attractive option for risk-averse investors as well as for any portfolio manager during severe market downturns and periods of excess volatility. 


\section{References}

Abdelsalam, O., Fethi, M. D., Matallín, J. C., \& Tortosa-Ausina, E. (2014). On the comparative performance of socially responsible and Islamic mutual funds [Supplement]. Journal of Economic Behavior and Organization, 103, 108-128.

Abdullah, F., Hassan, T., \& Mohamad, S. (2007). Investigation of performance of Malaysian Islamic unit trust funds: Comparison with conventional unit trust funds. Managerial Finance, 33(2), 142-153.

Cuthbertson, K., Nitzsche, D., \& O'Sullivan, N. (2010). The market timing ability of UK mutual funds. Journal of Business Finance and Accounting, 37(1-2), 270-289.

Derwall, J., Guenster, N., Bauer, R., \& Koedijk, K. (2005). The eco-efficiency premium puzzle. Financial Analysts Journal, 61(2), 51-63.

Ernst \& Young. (2012). The world Islamic banking competitiveness report 2012/13: Growing beyond: DNA of successful transformation. Retrieved from http://www.ey.com/Publication/vwLUAssets/The_World_Islamic _Banking_Competitiveness_Report/\$FILE/World\%20Islamic\%20Ba nking\%20Competitiveness\%20Report\%202012-13.pdf

Fama, E., \& French, K. (1993). Common risk factors in the returns on stocks and bonds. Journal of Financial Economics, 33(1), 3-56.

Forte, G., \& Miglietta, F. (2011). A comparison of socially responsible and Islamic equity investments. Journal of Money, Investment and Banking, 21, 116-132.

Geczy, C., Stambaugh, R. F., \& Levin, D. (2005). Investing in socially responsible mutual funds. Unpublished manuscript, University of Pennsylvania, The Wharton School, Philadelphia, PA.

Goodhart, C. A. E. (2008). The regulatory response to the financial crisis. Journal of Financial Stability, 4(4), 351-358.

Gregory, A., \& Whittaker, J. (2007). Performance and performance persistence of 'ethical' unit trusts in the UK. Journal of Business Finance and Accounting, 34(7-8), 1327-1344. 
Hayat, R., \& Kräussl, R. (2011). Risk and return characteristics of Islamic equity funds. Emerging Markets Review, 12(2), 189-203.

Hoepner, A. G., Rammal, H. G., \& Rezec, M. (2011) Islamic mutual funds' financial performance and international investment style: Evidence from 20 countries. European Journal of Finance, 17(9-10), 829-850.

Jensen, M. C. (1968). The performance of mutual funds in the period 19451964. Journal of Finance, 23(2), 389-416.

Jiang, W. (2003). A nonparametric test of market timing. Journal of Empirical Finance, 10(4), 399-425.

Kon, S. J. (1983). The market-timing performance of mutual fund managers. Journal of Business, 56(3), 323-347.

Patro, D. K. (2001). Measuring performance of international closed-end funds. Journal of Banking and Finance, 25(9), 1741-1767.

Pesaran, M. H., \& Smith, R. (1995). Estimating long-run relationships from dynamic heterogeneous panels. Journal of Econometrics, 68(1), 79-113.

Renneboog, L., Ter Horst, J., \& Zhang, C. (2008). The price of ethics and stakeholder governance: The performance of socially responsible mutual funds. Journal of Corporate Finance, 14(3), 302-322.

Treynor, J. L., \& Mazuy, K. K. (1966). Can mutual funds outguess the market? Harvard Business Review, 44, 131-136. 
